\title{
Development of alternating current circuit simulation as essential learning support for senior high school student
}

\author{
Mayang Dwinta Trisniarti, Pujayanto \\ Physics Education Department of Sebelas Maret University, \\ J1. Ir. Sutami 36A Kentingan Jebres Surakarta 57126, INDONESIA \\ E-mail: mayangdwinta@gmail.com
}

\begin{abstract}
In this study an interactive simulation of Alternating Current circuit was developed by using Articulate Storyline 2 and Adobe Flash CS 6 programs. The aim of this study was providing a computer interactive simulation as essential learning support for Senior High School student. One of the most important features of AC circuit simulation is the easily and continuous material to attain learning objectivity and interest toward students. This AC circuit simulation is built to create real-time sine wave graphs so that student could compare the result if the variable were changed gradually. The validation is held through several experts and reviewers due to get obtained through questionnaires. The results of this research could be concluded that AC circuit simulation for Senior High School Physics have good criteria based on user interface, i.e. 50\% of respondents rated enough, $16.67 \%$ of respondents rated good, and $33.33 \%$ of respondents rated very good. Based on maintenance, i.e. $50 \%$ of respondents rated enough, $20 \%$ of respondents rated good, and $30 \%$ of respondents rated very good. Then based on usability, i.e. $6.67 \%$ of respondents rated good and $93.33 \%$ rated very good. Furthermore, based on understanding, i.e. $6.67 \%$ of respondents rated enough, $30 \%$ of respondents rated good, and $73.33 \%$ of respondents rated very good. The use of AC circuit simulation could improve the senior high school students' cognitive ability on the Physics's course, i.e. with the average score increased from 68.67 to 80.5 based on 30 students.
\end{abstract}

\section{Introduction}

Recently, the information and communication technology has witnessed a big influence in all fields. Science is obviously connected with technology, both theoretically and practically. Conception of learning natural sciences i.e. Physics are dependent on learning environment [1]. Yet, educational development in teaching Physics considers the importance of using computer to facilitate studying many Physics phenomena that cannot be obtained experimentally due to its danger effects, abstract characteristic, unaffordable cost, less time to complete the experiment, and lack of laboratory facilities [2]. The environment of computer-based learning in Physics could give a significant impact toward students. Moreover, a technology-enriched field in Physics would greatly improve students' interest [3]. A computer simulation, which is enabled essential function of experiments to be carried out on a computer, is called interactive simulation [4-5]. Study emphasized the vital role of computer simulation in developing academic achievement, providing awareness of scientific concepts, and modifying misconceptions 
held by Al-Sharhan was concluded that virtual labs in teaching science could be a booster toward student to understand the scientific concept because they study science visually through simulation.

Electrical current and its scopes regards to direct current (DC) and alternating current (AC) are parts of contextual Physics phenomena which cannot be shown as real thing just based on real experiment. Students cannot see the waves created by electrical current so that they need a guided simulation to develop their understanding about electrical current [6]. This paper using Alternating Current Circuit (AC Circuit) simulation developed by Articulate Storyline 2 and Adobe Flash CS 6 programs is aimed to create essential learning support for Senior High School student.

\section{Methods}

In this article, various interface of combining the several interactive simulations has been investigated. Simulation is a computer assisted instruction which enables essential functions of laboratory experiments [7]. The experiments were conducted by synthesizing components to provide the essential simulation such as course material, picture, and video. Those are combined by using Adobe Flash CS 6 and Articulate Storyline 2. The outcome was interactive simulation which can be used as guided interactive simulation for students as essential learning support.

After the simulation has been done, validation was applied through several respondents. i.e. two experts in Physics simulations, four peer reviewers, and four chosen reviewers due to get obtained through questionnaires [8]. After had been reviewed, AC circuit lab virtual was implemented through ten students as first try out. The result from ten students as respondents was used to revise the simulation in order to provide better and essential learning support in Physics course i.e. AC circuit material. The flowchart of researchs' methods is shown in Figure 1.

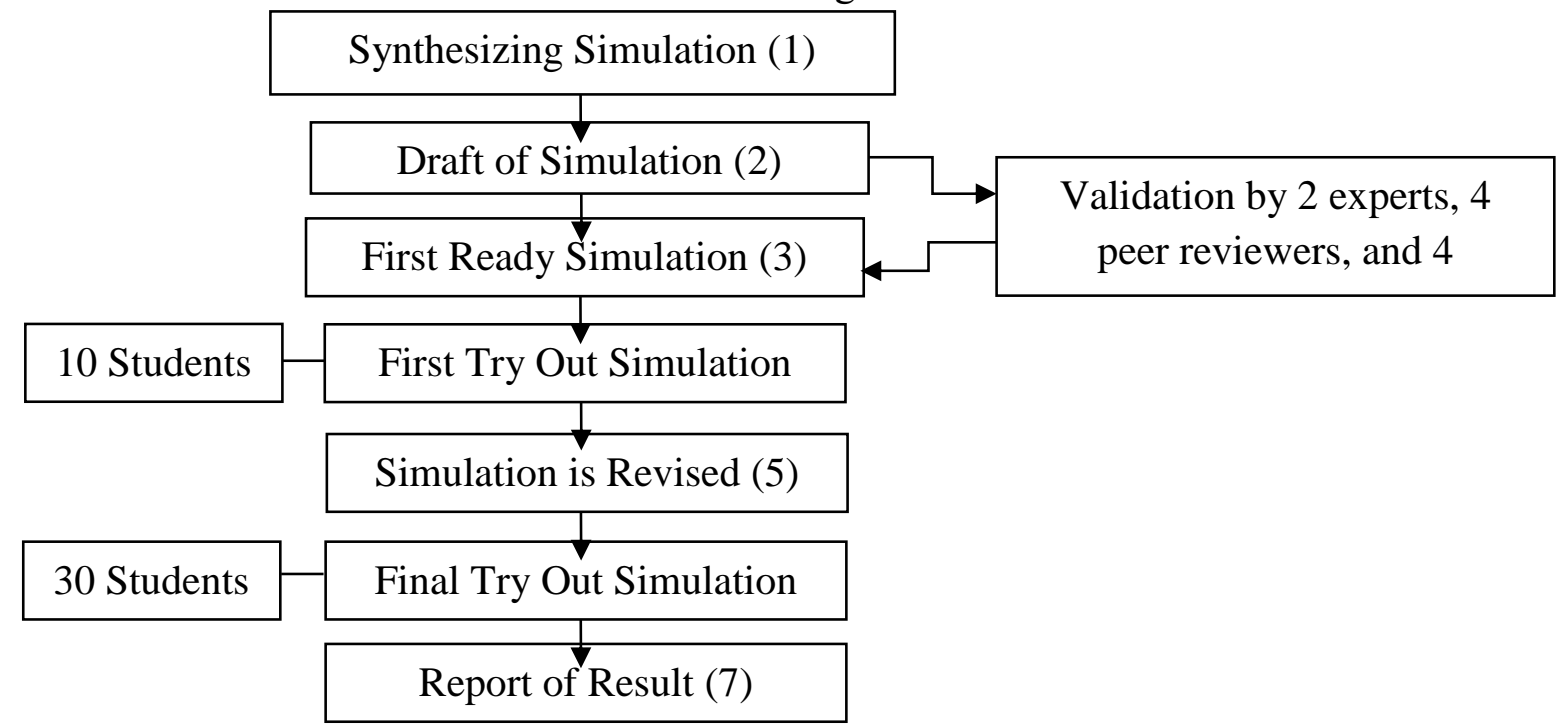

Figure 1.The flowchart of researchs' methods. Every step was held week by week in order to get optimum result in the end. Report of result consists of the questionnaries through for criterias and student's cognitive data gained by the paper test in SMA N 3

Surakarta. 


\section{Results and Discussion}

The result of the experiment was an interactive simulation about Alternating Current Circuit for Senior High School students. This media consisted of term of use, concept map, material, quiz, and eight interactive simulations. Those are AC Generator, Single Component of RLC, RL Series Circuit, RC Series Circuit, RLC Series Circuit, RL Parallel Circuit, RC Parallel Circuit, and RLC Parallel Circuit. Those could present realtime sine wave based on the variable changing gradually. So that student could understand the impact of each variable in every time. This simulation was implemented in Senior High School for the first time in order to get some reviews from ten students. This simulation was also shown to experts and peer reviewers to get some additional advice. Then, it was revised by considering the result from reviewers. The revised simulation was applied again in final try out for 30 students in XII Science 4 of Senior High School 3 Surakarta. The simulations' interface is shown in Figure 2 and Figure 3.

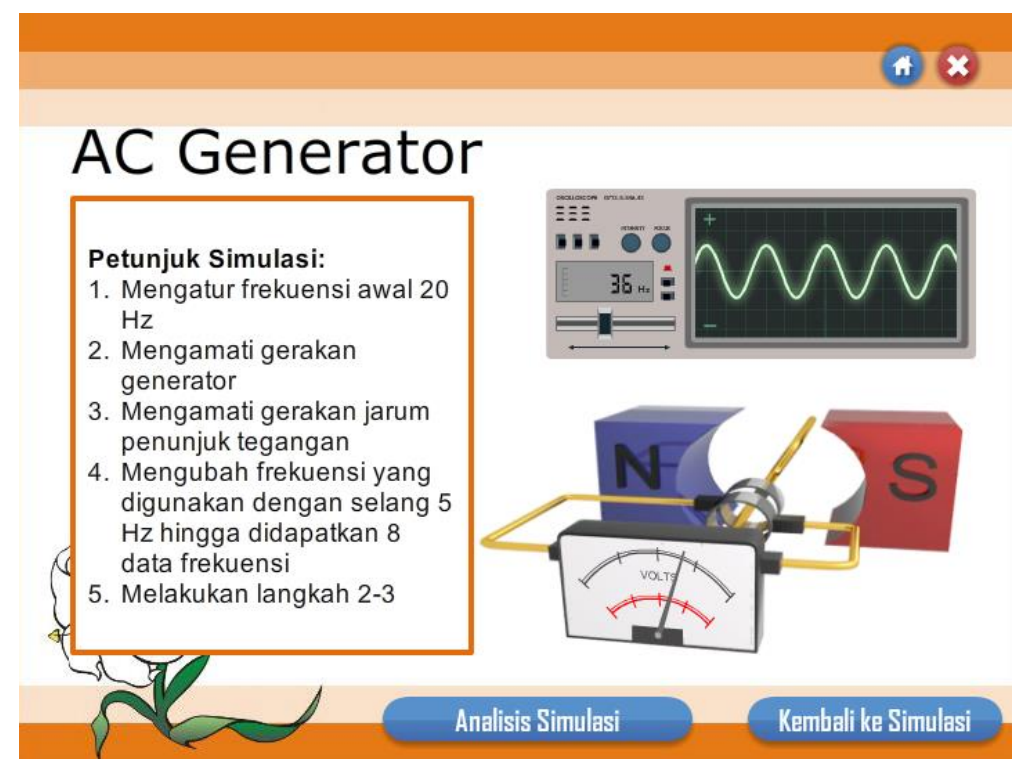

Figure 2.The first simulation of AC Generator to present the sine wave in virtual oscillloscope. As long as the student changes the frequency, the graphs and the magnetic field will be changed too. So that student can see the differences among each frequency. 


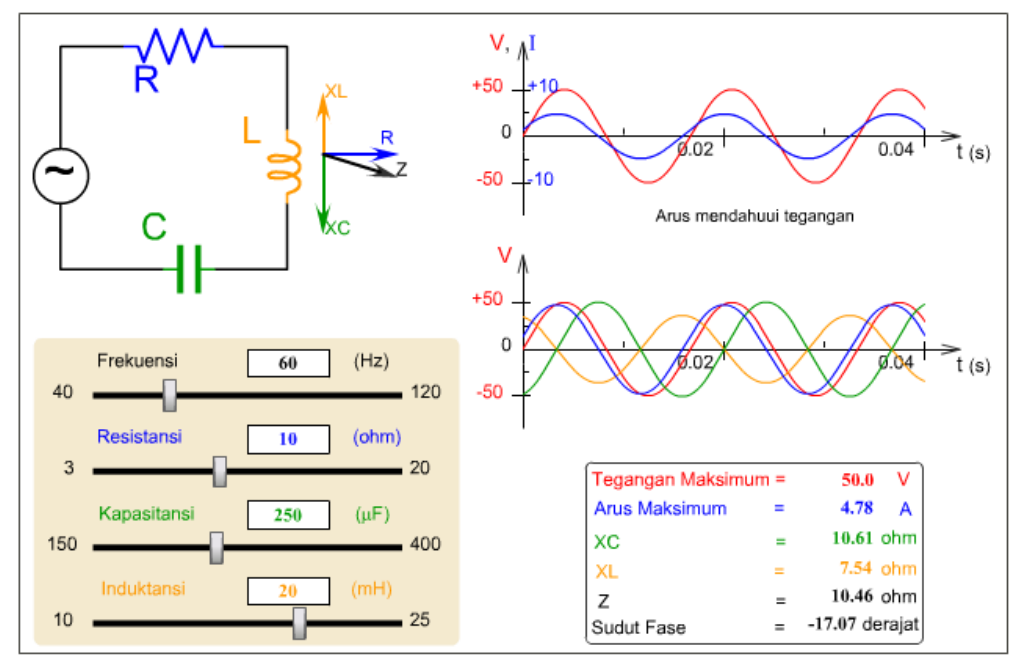

Figure 3.The second simulation about RLC Series Circuit to present the sine wave virtually in real-time. As long as the student changes the frequency, resistance, capasitance, and inductance, the graphs and the magnetic field will be crawled too. So that student can see the differences among each variables.

The results of this research could be concluded that AC circuit simulation for Senior High School Physics have good criteria based on user interface, i.e. 50\% of respondents rated enough, $16.67 \%$ of respondents rated good, and $33.33 \%$ of respondents rated very good. Based on maintenance, i.e. $50 \%$ of respondents rated enough, $20 \%$ of respondents rated good, and $30 \%$ of respondents rated very good. Then based on usability, i.e. $6.67 \%$ of respondents rated good and $93.33 \%$ rated very good. Furthermore based on understanding, i.e. $6.67 \%$ of respondents rated enough, $30 \%$ of respondents rated good, and $73.33 \%$ of respondents rated very good. It is persistently showed in Figure 3.

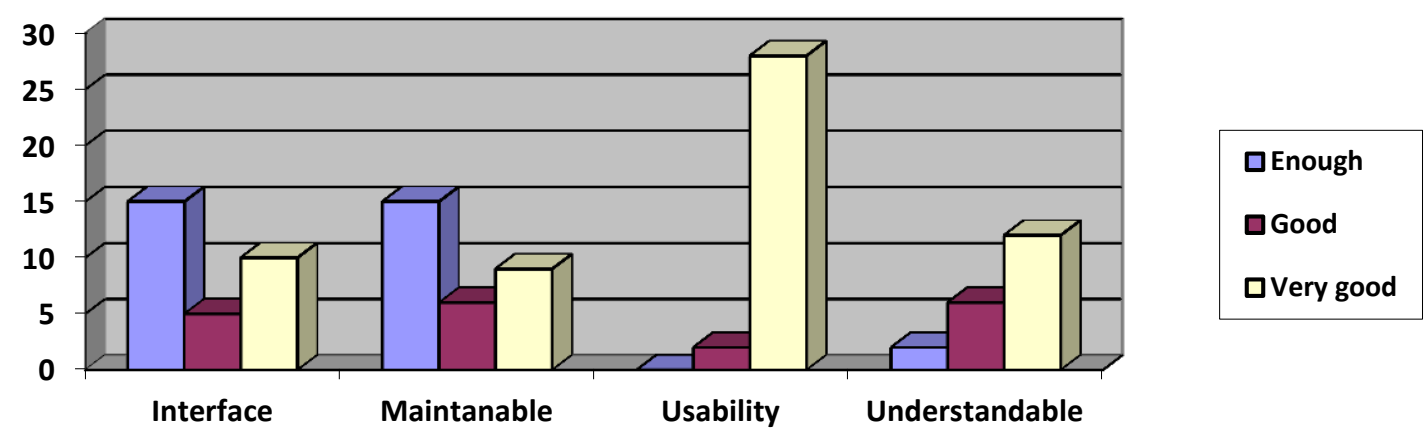

Figure 4. The graph based on reviewers in order to know about AC circuit simulations' criterias. Those are user interface, maintanability, usability, and understandable which run into 30 respondents in the end of the final try out of simulation.

After students got to study in case of this simulation, AC circuit simulation, paper and pencil test was held to measure the students understanding toward material. The students' cognitive ability in previous material before using the simulation (Faradays' Law) was 68.67 based on average score measurement. After using AC circuit simulation 
in Alternating Current circuit material, the average score increased to 80.5 based on 30 students.

In conclusion, the simulation can be used as an essential learning support for senior high school student. This kind of educational technology provides an advanced individualized learning perfectly [9]. Simulation also provides higher level of flexibility from constrains of time and place so that students are interested to learn Physics though the subjects are abstract [10]. One of the most important features of AC circuit simulation is the easily and continuous material to attain learning objectivity and interest toward students. In the other hand, the use of AC circuit simulation could also improve the senior high school student's cognitive ability on the Physics' course i.e. with the enhancement of average score from 68.67 to 80.5 based on 30 students.

\section{References}

[1] Huda M 2011 IPCSIT Press Singapore. 12654

[2] Al-Shaie 2006 Journal King Saudi University. 19 441-497

[3] Mayang D and Nur Ulfah C 2015 Journal Yogyakarta University. 18 12-16

[4] Ulrich H 1998 IEEE Mult. Education. 51483

[5] Kolar, Sabatini L and Fink L 2002 Journal of Engineering Education. 91 397-401

[6] Yu K 2016 IOP Science1742-6596. 675012001

[7] Breen M 2015 IOP Science 755-1315. 32112061

[8] Putri U 2012 Journal of Sciences ITB. 118201345

[9] Aniello C, Giuseppe C and Luigi C 2012IEEE Trans. Magn.58 13116927

[10] Maziar A, Christophe M, Majid N, Mohammad J and Andre S 2013 Bioinspir. Biomim. 8036002 